\title{
Un lituano en París (en torno a un recorrido transfronterizo de la fenomenología)
}

\author{
Silvana Rabinovich
}

Este texto aborda a Emmanuel Levinas en tanto introductor de la fenomenología en Francia. Se trata de pensar al filósofo como traductor en el sentido amplio del término: tomando como pretexto su traducción al francés (en colaboración) de las Meditaciones cartesianas de Husserl, se plantea un recorrido de la obra (fenomenológica) levinasiana en cinco "gestos filosóficos" que relacionan su pensamiento con los avatares de la política del siglo xx. Así, el filósofo lituano da asilo en París a la filosofía de un judío alemán en la medianoche del siglo.

Palabras Clave: Levinas, fenomenología, filosofía, política, traducción.

This text focuses on Emmanuel Levinas as the introducer of phenomenology in France. It aims at studying the philosopher as a translator in the wide sense of the term. Taking his French translation (in collaboration) of Husserl's Meditations Cartessiennes as a point of departure, I go through the levinasian (phenomenological) writings uncovering five "philosphical gestures" which relate his thoughts with the political scenarios of the $20^{\text {th }}$ Century. Thus, a German Jew's philosophy is sheltered by the Lithuanian philosopher in Paris at the darkest times of the century. 

Silvana Rabinovich

Instituto de Investigaciones Filológicas, UNAM

\section{Un lituano en París (en torno a un recorrido transfronterizo de la fenomenología) ${ }^{1}$}

La obra del filósofo Emmanuel Levinas (Kaunas 1906-París 1995) marcó un cambio de dirección en el pensamiento ético del siglo xx. A contracorriente de una tradición filosófica que pone el acento en la autonomía, Levinas planteó la ética heterónoma como filosofía primera. Para esto fue necesario previamente desarticular la dicotomía autónomo/heterónomo y formular en términos positivos una subjetividad pensada ante todo en su relación con el otro, pasiva (es decir, no inactiva, sino capaz de ser afectada), en el marco de un tiempo que asume la forma de la paciencia. En su formación filosófica, al adaptar a sus preocupaciones el método fenomenológico, el autor se reconoce como discípulo de Edmund Husserl. Este filósofo alemán dedicó su vida a restituirle a la filosofía el lugar de "ciencia estricta", liberándola del empequeñecimiento al que el positivismo la había orillado y de las ataduras de los presupuestos metafísicos. Levinas tradujo una de las Meditaciones cartesianas del maestro de Friburgo al francés y de esta manera introdujo la fenomenología

${ }^{1}$ Una versión preliminar de este trabajo fue presentada como conferencia en el Centro Franco-Argentino de Altos Estudios, Universidad de Buenos Aires (7 de noviembre de 2005). 
en Francia. El filósofo lituano tenía un punto de vista crítico hacia cierto intelectualismo que se desprendía de la fenomenología estática del maestro de Friburgo, hizo escuchar en francés las resonancias de los aspectos genéticos del método. Levinas declara en todo momento que su método es el fenomenológico, teniendo como punto de partida en su propio pensamiento a la génesis pasiva husserliana. ${ }^{2} \mathrm{El}$ trabajo que sigue intenta hacer un breve recorrido metafórico de su obra en el marco de los acontecimientos políticos que marcaron su pensamiento filosófico. No se trata de abordar en la totalidad el pensamiento levinasiano (quien conoce la crítica levinasiana a la totalidad sabe que ese sería un camino condenado al fracaso), sino de invitar al lector a aproximarse a Levinas por el camino donde ética y política se entretejen en una "poética de la traducción". Para tal fin, se presentan cinco etapas de la escritura levinasiana como cinco "gestos" que abarcan diversos aspectos puntuales de la vida y obra del filósofo en el marco histórico-político correspondiente, y al final de cada "gesto" aparece un listado de los libros publicados por el autor en el periodo indicado.

\section{Un lituano en París}

La misión del traductor es rescatar ese lenguaje puro confinado en el idioma extranjero, para el idioma propio, y liberar el lenguaje preso en la obra al nacer la adaptación.

WALTER BeNJAMin

Quisiera referirme al filósofo lituano en tanto que introductor $^{3}$ - o para utilizar un término en boga y en este caso bas-

${ }^{2}$ En la "Cuarta meditación” de las Meditaciones cartesianas, §38 y 39, Husserl desarrolla la noción de génesis pasiva, que aborda todo aquello que es dado previamente, sin mediación de la actividad del sujeto. Esto resuena en la pasividad levinasiana.

${ }^{3}$ Cfr. prólogo a Théorie de l'intuition dans la phénoménologie de Husserl, 5-8. Jean Hering (teólogo protestante de origen alsaciano) había introducido en Francia 
tante preciso: fue passeur - de la fenomenología en Francia. Como esta introducción de Husserl en Francia se debe a una traducción, pondré el acento en la singularidad de este filósofo traductor (la tarea del traductor-introductor se desarrolla evidentemente en la transferencia lingüística del texto de las Meditaciones cartesianas -en colaboración con Gabrielle Pfeiffer-, pero también en la escritura de la Teoría de la intuición en la fenomenología de Husserl ${ }^{4}$ y, aún más lejos - $-\mathrm{y}$ un poco más tarde- en el transcurso de la ética levinasiana). La traducción —en el sentido amplio del término — permite la recepción del método husserliano en Francia, que — tomando prestada la expresión de Levinas - me atreveré a ubicar bajo el signo del "presentimiento" (Levinas, Difficile Liberté, 374) del nazismo. La traducción levinasiana da asilo en la lengua y el suelo francés a un pensamiento alemán que —unos años más tarde- será desterrado por causa de una firma donde se cifra un nombre judío. Se trata, entonces, de un judío lituano —un extranjero- que da asilo a un pensamiento alemán en Francia: es un trabajo fino de transferencia; podríamos arriesgarnos a decir, tal vez, de contrabando. En este acto de traducción de un pensamiento filosófico que anuda la verdad con la vida, no se produce un pasaje de la lengua del otro a la lengua propia; evocando el epígrafe de Benjamin, este "lenguaje puro" rescatado no cesa de ser exiliado. Y atribuirle esta compleja expresión benjaminiana $^{5}$ a la escritura de Husserl, implica dejar traslucir

algo del pensamiento de Husserl, pero se reconoce a Levinas como traductor e introductor. A él se debe, junto a Gabrielle Pfeiffer, la traducción —en 1931— de la "Quinta meditación", relativa a la intersubjetividad.

${ }^{4}$ Se trata de la tesis doctoral de Levinas, publicada en 1930 y que muchos, entre ellos Derrida, consideran como la introducción de la fenomenología en Francia.

${ }^{5}$ Benjamin se refiere en su texto "La tarea del traductor" al lenguaje adánico y esa no es una preocupación del filósofo de Friburgo. Sin embargo, es aplicable el término al lenguaje de la fenomenología, que con la reducción eidética busca llegar "a las cosas mismas", libre de presupuestos y prejuicios, dando lugar a una descripción que tiene pretensiones de cierta pureza. 
el objetivo de la fenomenología que es llegar "a las cosas mismas" (zu den Sachen selbst).

A comienzos de 1930, el filósofo lituano logra que el método de pensamiento de su maestro pase la frontera. Y este "salvamento" permite que una filosofía, que en su Alemania natal quedará en exilio académico —orillada a la versión de la ontología fundamental heideggeriana-, franquee la valla fronteriza y pueda huir de aquello que Levinas llamará el encadenamiento como rasgo fundamental de "la filosofía del hitlerismo". ${ }^{6}$ Despojada de sus cadenas, una vez en suelo francés donde campeaba el bergsonismo, la fenomenología — desterritorializada - no cesará de recorrer caminos de pensamiento divergentes. El método fenomenológico, especie de "judío errante" ${ }^{7}$ del pensamiento del siglo $\mathrm{xx}^{8}{ }^{8}$ inicia el recorrido de los exiliados: será el extranjero quien, a la manera del traductor, intentará cabalgar sobre dos culturas, aprovechando —-paradójicamente- aquello que el historiador Enzo Traverso atribuye a los exiliados: a saber, un cierto "privilegio epistemológico del exilio". ${ }^{9}$ Desde el punto de vista de la pretensión de universalidad característica de la filosofía, podríamos poner en cuestión esta transposición de ideas y personas exiliadas (evidentemente

${ }^{6}$ Cfr. Levinas, Algunas reflexiones sobre la filosofía del hitlerismo, p. 16.

${ }^{7}$ En el contexto histórico de la Alemania nazi que la orillaba a la versión heideggeriana, la obra del judío Husserl pudo seguir otros rumbos en el exilio. Utilizo esa expresión tan hostil para los judíos ("judío errante"), no con el fin de afirmar la postura moralizante que la sostiene, sino justamente — siguiendo a Judith Butler — para "agenciarla", esto es: activar su efecto crítico en contra de la impostura que la formula. Cfr. Butler, Lenguaje, poder e identidad.

${ }^{8}$ La fenomenología tuvo la historia que Ricoeur denominó como "herejías husserlianas" (empezando por Levinas y Heidegger, pero la lista es larga). Sartre marcó cierta lectura de Husserl de la que otros trataron de desligarse. Tal es el caso de Derrida, que se reconoce heredero de la fenomenología husserliana aun cuando la critica. Él entiende a la deconstrucción como un "gesto fenomenológico" (el cual apunta a liberarse de las presuposiciones en su camino "a las cosas mismas") que busca poner en evidencia los presupuestos que la fenomenología no fue capaz de erradicar en ella misma (cfr. Derrida, "Entrevista con Antoine Spire").

${ }^{9}$ Cfr. Traverso, Cosmópolis. Figuras del exilio judeo-alemán. 
un pensamiento no es una persona, pero en términos políticos es muy difícil separarlos: esto remite al componente subjetivo y político inherente al pensamiento). En los totalitarismos se persiguen las ideas al igual que a las personas que se acercan a ellas, se queman libros; el caso de Husserl en Friburgo es paradigmático. ${ }^{10}$ Singular, universal: evocando a Benjamin, siempre se parte de lo singular para alcanzar lo universal. ${ }^{11}$ Los filósofos (incluso Aristóteles, como lo demostró bien Benveniste) ${ }^{12}$ escriben en una lengua particular, y —agreguemos- las circunstancias políticas en las cuales se encuentran provocan la búsqueda de líneas de fuga que se expresan a veces bajo el signo de la aspiración a lo universal.

Esta filosofía en exilio, que tiene por tarea preguntar fuera de todo presupuesto, permite al filósofo traductor — responsable de su asilo- darle la palabra a la génesis pasiva, ${ }^{13}$ en francés, en el entrecruzamiento de diversas lenguas (el ruso, el alemán, el hebreo y, en el trasfondo, también el jargon, esto es, el yídish).

Quisiera aprovechar la "mala fama" de la traducción (debida a todas las sospechas de inexactitud, de confusión —en el sentido babélico del término-e incluso de tristeza o de melanco-

${ }^{10}$ En 1933 tuvo lugar el "bibliocausto" nazi: la búsqueda frenética —para la quema masiva - por las bibliotecas de Alemania de libros de autores judíos y/o comunistas apodada así por la revista Time de mayo de ese año. Heidegger tuvo un gesto ambiguo: si bien borró la dedicatoria a Husserl que en 1927 figuraba en su libro Ser y tiempo, no permitió que esa hoguera tuviera lugar en su universidad y en tanto catedrático siguió refiriéndose a la obra de su maestro.

${ }^{11}$ Cfr. Wohlfarth, Hombres del extranjero, p. 57 y la nota 59 a pie de página con relación a ciertos textos de Benjamin como El origen del drama barroco alemán.

${ }^{12}$ Benveniste, Problemas de lingüística general, 63-74, cap. "Categorías del pensamiento y categorías de la lengua".

${ }^{13}$ Debe notarse que, además de la fenomenología estática — marcada por la suspensión de los presupuestos metafísicos en el conocimiento conocida como reducción fenomenológica-, Levinas se interesa por la génesis pasiva desarrollada por Husserl, que pone el acento en el momento pasivo de la constitución trascendental, en el abordaje de la temporalidad constituyente de la conciencia (cfr. Husserl, Meditaciones cartesianas, "Cuarta meditación” § 38 y 39) . 
lía) para volver a la figura aún peor afamada del contrabando. Este último tiene lugar al hacer pasar la frontera a una filosofía cuyo nombre "oficial" (digamos, el que figuraba en la "visa") era fenomenología estática, pero que una vez pasada la frontera sólo conserva el nombre de pila (fenomenología), dejando traslucir su nombre bajo el signo de la pasividad. Quisiera sugerir una perspectiva política de esta posición de Levinas: en los inicios de la fenomenología en Francia.

En este enfoque, voy a detenerme un momento en una parte de la "firma" de Levinas. Se trata del texto final de Difícil liber$\mathrm{tad}$, un fragmento bastante conocido y frecuentemente citado:

\section{Signature - Firma}

La Biblia hebrea desde la edad más temprana en Lituania, Pushkin y Tolstoi, la revolución rusa de 1917 vivida a los once años en Ucrania. Desde 1923, la Universidad de Estrasburgo donde enseñaban en ese momento Charles Blondel, Halbwachs, Pradines, Carteron y más tarde, Guéroult. Amistad de Maurice Blanchot y a través de los maestros que habían sido adolescentes en el momento del Caso Dreyfus, visión, para un recién llegado, deslumbrante, de un pueblo que iguala a la humanidad y de una nación a la que uno puede ligarse por el espíritu y el corazón tan fuertemente como por raíces. Estadía en 1928-1929 en Friburgo y aprendizaje de la fenomenología empezado un año antes con Jean Hering. En La Sorbona, Léon Brunschvicg. La vanguardia filosófica en las noches de sábado en lo de Gabriel Marcel. El refinamiento intelectual - y antiintelectualista - de Jean Wahl y su generosa amistad reencontrada después de un largo cautiverio en Alemania; conferencias regulares desde 1947 en el Colegio filosófico que Wahl había fundado y animaba. Dirección de la centenaria Escuela Normal Israelita Oriental, formando maestros franceses para las escuelas de la Alianza Israelita Universal de la Cuenca Mediterránea. En comunión cotidiana con el doctor Henri Nerson, frecuentación de Monsieur Chouchani, maestro prodigioso - $\mathrm{y}$ despiadado- de exégesis y de Talmud. Conferencias anuales, 
desde 1957, sobre los textos talmúdicos, en los coloquios de los intelectuales judíos de Francia. Tesis de doctorado en 1961. Profesorado en la Universidad de Poitiers, desde 1967, en la Universidad de París-Nanterre y, desde 1973, en la Sorbona. Este inventario disparatado es una biografía.

Está dominada por el presentimiento y el recuerdo del horror nazi (Levinas, Difficile Liberté, 373 y 374, trad. mía).

He aquí la firma plurilingüe de un filósofo judío nacido en Lituania, que aprendió el método fenomenológico en Friburgo — con Husserl y Heidegger entre los años 1928 y 1929 y que por su propia elección quedó ligado "por el espíritu y el corazón" a la cultura francesa. Firma llena de "nombres propios", ${ }^{14}$ pertenecientes a otras personas, entrecruzamientos de diversos recorridos filosóficos; firma que designa amistades. Este judío aprendió a leer las cuadradas letras hebreas al mismo tiempo que el ruso y su lengua vernácula. Discípulo de un "sin domicilio" por definición: su maestro de Talmud de memoria prodigiosa era tan enigmático que él mismo era sospechoso de contrabando. ${ }^{15}$ Un filósofo, lector de literatura rusa, de la Biblia en hebreo y del Talmud. Traductor desde siempre: passeur (intermediario) entre varias lenguas. ${ }^{16}$ Una vida bastante cosmopolita (en el sentido fuerte del término, al modo de los exiliados, de los apátridas), que atravesó el tiempo bajo el signo del temor: del presentimiento al recuerdo del odio. Levinas trataba - fuera de todo presupuesto- de revertir el sentido de la filosofía: ${ }^{17}$ de encon-

\footnotetext{
${ }^{14}$ El entrecomillado se debe a que la ética heterónoma (no sólo en Levinas, sino a través de Rosenzweig) obliga a poner en cuestión la propiedad del nombre, que siempre es dado por otro y que es la puerta que conecta al sujeto con el pasado y el porvenir.

${ }^{15}$ Cfr. Malka, Monsieur Chouchani. L'énigme d'un maître du xxe siècle.

${ }^{16}$ Durante la Segunda Guerra Mundial, el filósofo se enroló en el ejército francés como traductor (luego cayó prisionero).

${ }^{17}$ Claro que no se trata de volver a los orígenes ni tampoco de salir del campo de la filosofía, no se encamina hacia lo pre-filosófico. Se trata más bien de exigir a la filosofía la reconsideración del rol de la ética, Levinas insta a la tradición del pensamiento occidental a responder por el otro.
} 
trar en ella — lejos de cualquier tono edulcorado — la "sabiduría del amor al servicio del amor" (Levinas, Autrement qu'être, 207). En tanto testigo de su tiempo, el filósofo escribía:

Las guerras mundiales - y locales-, el nacional-socialismo, el stalinismo -e incluso la desestalinización-, los campos, las cámaras de gas, los arsenales nucleares, el terrorismo y la desocupación - es mucho para una sola generación, de lo que ella sólo ha sido testigo (Levinas, Noms Propres, 7). ${ }^{18}$

Bajo el peso del "mucho"19 ante el que esta generación fue expuesta, pensemos la filosofía levinasiana como un acto de "resistencia" prolongado a lo largo de toda su vida filosófica: un acto cuyo comienzo se encontraba bajo el signo del presentimiento del horror y cuya continuación fue dedicada a su memoria; es la traducción contrabandista de la fenomenología, en cinco gestos filosóficos aparecidos sucesivamente, pero que siempre coexistieron. La palabra gesto es adecuada debido a la sutileza de la transmisión que comporta. Al modo de la huella, el gesto no es signo, no se reduce a ningún significado. La filosofía no se transmite solamente a través de argumentos: en las interlíneas de la gesta del pensamiento occidental, algunos gestos filosóficos se deslizan permitiéndonos, en este caso, leer el recorrido de un pensamiento sensible que confiesa estar atravesado por el horror. En lo que sigue, cinco gestos filosóficos levinasianos, un recorrido - repito, contrabandista, de exilio y por lo tanto no exhaustivo - de la fenomenología en Francia:

\footnotetext{
18 "Les guerres mondiales —et locales_, le national-socialisme, le stalinisme —et même la déstalinisation - les camps, les chambres à gaz, les arsenaux nucléaires, le terrorisme et le chômage — c'est beaucoup pour une seule génération, n'en eût-elle été que témoin" (Levinas, Noms propres, 7 ).

${ }^{19}$ Me permito utilizar el adverbio como sustantivo evocando la plegaria fundamental del judaísmo, "Shemá" (Deuteronomio 6:5), donde se ordena amar a Dios con todo "tu corazón, con toda tu alma y (si traducimos literalmente) con todo tu mисho" (meodeja). Esta extraña expresión se refiere al exceso: en el caso bíblico, de amor; en el de la cita, de sufrimiento.
} 
— Primer gesto: "Pasando la frontera" (gesto académico, desde 1930).

Obra:

Théorie de l'intuition dans la phénoménologie de Husserl (TIPH) [1930], Paris, Vrin, 1963.

Introducción de la fenomenología estática, presentación de la teoría de la intuición en la fenomenología de Husserl. Respecto a la traducción: el "lenguaje puro" benjaminiano evoca esta intuición desarrollada por el retorno a las cosas mismas (zu den Sachen selbst), que es la intuición buscada por el gesto fenomenológico. Traducción al francés, en 1931, de las Meditaciones cartesianas de Husserl, introducción de la génesis pasiva (“Cuarta meditación”, §38 y 39).

— Segundo gesto: "El éxodo necesario" (1934-1935, académico pero también político).

Obra:

Quelques réflexions sur la philosophie de l'hitlérisme (QRPH) [1934], en Payot et Rivages, Paris, 1997. Trad. al español: Algunas reflexiones sobre la filosofía del hitlerismo, Fondo de Cultura Económica, Buenos Aires, 2001.

"L'actualité de Maïmonide" [1935], en revista Paix et Droit, abril de 1935.

De l'évasion (DE) [1935], Fata Morgana, Montpellier, 1982. Trad. al español: De la evasión, Madrid, Arena Libros, 1999.

Bajo el signo de la inquietud política: debido al "privilegio epistemológico del exilio", Levinas aborda el hitlerismo a partir del método fenomenológico (Algunas reflexiones sobre la filosofía del hitlerismo). Temor al "mal elemental":20 el de per-

${ }^{20}$ Ver Quelques réflexions sur la philosophie de l'hitlérisme. "Post-scriptum", cfr. también el importante estudio de Miguel Abensour, "El mal elemental", en la misma edición. 
manecer "orillado" al ser. ¿(Meta)fenomenología quizás? En el marco de un abordaje fenomenológico de la fenomenología heideggeriana, el filósofo lituano ahonda la separación entre el "estado de yecto" (Geworfenheit) y el proyecto (Entwurf): el "estado de yecto" se descubre ya bajo el signo del encadenamiento al ser. ${ }^{21}$ De la evasión, 1935: punto de viraje; Levinas desvía el camino de la fenomenología en su versión ontológica; en adelante, se tratará de salir del ser.

— Tercer gesto: "La muerte del otro" (académico, político y metafísico: en el sentido ético). ${ }^{22}$

Obra:

De l'existence à l'existant (DEE) [1947], Paris, Vrin, 1990. De la existencia al existente Trad. al español: Madrid, Arena Libros, 2000.

Le temps et l'autre (TA) [1948], Presses Universitaires de France, Paris, 1983. Trad. al español: El tiempo y el otro (TO), Barcelona, Paidós, 1993

En découvrant l'existence avec Husserl et Heidegger (EDE) [1949], Paris, Vrin, 1988. Trad. parcial al español en La Huella del Otro (HO), México, Taurus, 2000

"Quand les mots reviennent de l'exil", en Cahiers de l'Alliance Israélite Universelle, abril 1949.

Liberté et commandement (LC) [1953], Montpellier, Fata Morgana, 1994. Trad. al español: "Libertad y mandamiento" (LM) en La Huella del Otro, México, Taurus, 2000.

${ }^{21}$ Cfr. J. Rolland, "Sortir de l'être par une nouvelle voie", en Levinas, De l'évasion.

${ }^{22}$ Levinas sostiene, en Totalidad e infinito, que sin contradecir a Aristóteles (quien definía a la metafísica como filosofía primera), él la interpretaba etimológicamente, como aquello que está más allá de mi naturaleza, es decir, la relación con el otro: la ética. 
Totalité et Infini (TI) [1961], La Haye, Martinus Nijhoff, 1971. Trad. al español: Totalidad e infinito (TI), Salamanca, Sígueme, 1987.

Durante la guerra y después: desarrollo de la génesis pasiva. Surgimiento de la ética, al desviar el ontologismo: encaminamiento "de la existencia al existente", pensar el tiempo a partir del otro. Luego, Totalidad e infinito: "Aceptaremos fácilmente que es cuestión de gran importancia saber si la moral no es una farsa" (TI 47). Guerra, totalidad, el filósofo denuncia la complicidad en la tradición filosófica. La voz de Rosenzweig (¡demasiado presente para ser citado!) ${ }^{23}$ resuena, es el eco de la Primera Guerra Mundial:

La pluralidad de la nada que presupone la filosofía, la realidad de la muerte que no admite ser desterrada del mundo que se anuncia en el grito - imposible de acallar- de sus víctimas, convierten en mentira incluso antes de que sea pensado al pensamiento fundamental de la filosofía: al pensamiento del conocimiento uno y universal del Todo (Rosenzweig, La estrella de la redención, 45).

- Cuarto gesto: "Canon cultural" (posterior al desocultamiento de la mentira, gesto académico, político, metafísico y cultural, desde fin de los años cincuenta).

Obra:

Difficile Liberté (DL) [1963], Albin Michel, 1963 y 1995.

Quatre lectures talmudiques (QLT) [1968], Paris, Editions de Minuit, 1968.

"Le Dire et le Dit" (DD) [1971], en Le Nouveau commerce, cuaderno 18-19. Se incluye modificado en De otro modo que ser o más allá de la esencia.

${ }^{23}$ Cfr. Levinas, Totalidad e infinito, 54. 
Humanisme de l'autre homme (HAH), Montpellier, Fata Morgana, 1972. Trad. al español: Humanismo del otro hombre (HOH), México, Siglo XXI, 1974.

Surgimiento de la judeidad en la pasividad, es el tiempo de las lecturas talmúdicas (sin abandonar nunca la academia). Movimiento doble de la traducción: "[...] la posibilidad y la necesidad de saber decir —o de intentar decir— la Torá también en griego" (Á l'heure des nations, 63). Por eso, como en canon en la música, pensar a dos voces, entre dos horizontes culturales.

- Quinto gesto: "Cumplimiento de la evasión (exigida 40 años antes)" (académico, político, metafísico, cultural, hacia la constitución ética de la subjetividad: vulnerable, sensible).

Obra clave:

Autrement qu'être ou au-delà de l'essence, La Haye, Martinus Nijhoff, 1974. Trad. al español: De otro modo que ser o más allá de la esencia (DOMS), Salamanca, Sígueme, 1987.

Y a partir de esta obra clave, la que sigue su huella:

Sur Maurice Blanchot (SMB), Paris, Fata Morgana, 1975. Noms propres (NP), Paris, Fata Morgana, 1976.

Du sacré au saint, cinq nouvelles lectures talmudiques (DSS), Paris, Minuit, 1977.

"La révélation dans la tradition juive" [1977], en Ricoeur, Levinas et al., La révélation (LR), Bruxelles, Facultés universitaires Saint Louis, 1984.

L'au-delà du verset (ADV), Paris, Les éditions de Minuit, 1982.

De Dieu qui vient à l'idee (DQVI) [1982], Paris, Vrin, 1992. 
Trad. al español: De Dios que viene a la idea, Madrid, Caparrós, 1995.

Éthique et Infini-Dialogues avec Ph. Némo-, Fayard et Radio France, Paris 1982. Trad. al español Ética e Infinito, Madrid, Visor, 1991. Trad. al hebreo: E. Meir, Etica vehaEinsofi, Universidad de Jerusalem, 1995.

"Religión e idea del infinito" [1982], en Doce lecciones de filosofía, Barcelona, Ediciones Juan Granica, 1983.

Transcendance et Intelligibilité [1984], Genève, Labor et Fides, 1996.

Hors sujet (HS), Montpellier, Fata Morgana, 1987. Trad. al español: Fuera del Sujeto (FS), Madrid, Caparrós, 1997.

"Antlitz und erste Gewalt", Revista Spuren, Septiembre

1987. Trad. al español: "El rostro y la primera violencia" (RV), en La Huella del Otro, México, Taurus, 2000.

Autrement que savoir (AS), Paris, Osiris, 1988.

À l'heure des nations (HN), Paris, Minuit, 1988.

Entre nous. Essais sur le penser à l'autre (EN) [1991], Paris, Grasset, 1993. Trad. al español: Entre nosotros. Ensayos para pensar en otro, Valencia, Pre-textos, 1993.

La mort et le temps (MT), Paris, L'Herne, 1991. Dieu, la mort et le temps (DMT) Paris, Grasset et Fasquelle, 1991. Trad. al español: Dios, la muerte y el tiempo (DMT), Madrid, Cátedra, 1994.

Les imprévus de l'histoire (IH), Montpellier, Fata Morgana, 1994.

Altérité et transcendance (AT), Montpellier, Fata Morgana, 1995.

Nouvelles lectures talmudiques (NLT), Paris, Minuit, 1996.

Es el tiempo de la conciencia no intencional, ${ }^{24}$ pura pasividad de la conciencia pre-reflexiva, "Mala conciencia o timidez

${ }^{24}$ Levinas, "La conscience non intentionnelle" (ponencia presentada en la Universidad de Berna, 1983), en Poirié, Emmanuel Lévinas, 129-140. 
[...] del sin patria o sin domicilio" (Poirié, Emmanuel Lévinas, 136), separación del privilegio de lo teorético, de la representación, del saber: de otro modo que saber. Husserl siempre en el origen, pero:

a pesar de todas las sugerencias opuestas que igualmente pueden tomar de su obra: intencionalidad no teorética, teoría de la Lebenswelt [...] el papel del cuerpo propio y que Merleau-Ponty supo valorizar. Allí — pero también en los acontecimientos que se desplegaron de 1933 a 1945 y que el saber no supo ni evitar ni comprender- es la razón por la cual mi reflexión se separa de las últimas posiciones de la filosofía trascendental de Husserl o, al menos, de sus formulaciones (Poirié, Emmanuel Lévinas, 130, trad. mía).

El temor al mal elemental transcurre como temor ante la muerte del otro: "Temor por todo aquello que mi existir, a pesar de su inocencia intencional y consciente, puede cometer de violencia y de asesinato" (Poirié, Emmanuel Lévinas, 138). El otro, el prójimo, no es aquel que está próximo desde el punto de vista afectivo, ese "apátrida" que me conmina a acogerlo sensible y pasivamente; es —en palabras de Levinas- el prójimo que no me es próximo (Levinas, Noms Propres, 10). Pero todas las palabras sobrepasan sus sentidos corrientes. Así, la pasividad no se reduce a lo negativo de la actividad. La filosofía descubre su tarea en la traducción, rescatando la pasividad tras tantos siglos de hegemonía de la actividad. La fenomenología (pasada por contrabando) se transformó en la vía hacia la recuperación de la sensibilidad: ella da a la filosofía la contraseña (mot de passe, Schibboleth) ${ }^{25}$ para pronunciar la pasividad.

Volviendo al epígrafe de Benjamin: el "lenguaje puro" aparece bajo el signo del Decir al otro. El "lenguaje puro exiliado en la lengua extranjera" - “cautivo en la obra"- sería en el

${ }^{25}$ Cfr. Derrida, Schibboleth, pour Paul Celan. 
filósofo lituano el Decir anterior a lo Dicho. He aquí un descubrimiento inquietante en la perspectiva de la diacronía del tiempo: no hay lengua propia, la lengua siempre es impropia (sucia, desfasada, inapropiable). El sujeto, nacido en la lengua del otro, se sorprende "retrasado" (desfasado) respecto a sí mismo: su nombre no le pertenece (viene del otro y va hacia el prójimo). La ética levinasiana, en su movimiento hacia el otro, es un esfuerzo por rescatar el Decir, es la escucha del otro. Resonancia, tal vez, del "lenguaje puro" benjaminiano.

Este último gesto expresa la necesidad de permanecer en un incesante "estado de traducción": del alemán al francés, entre el hebreo y el griego. Siempre en la frontera, "sin patria", "sin domicilio". Condenado a errar, sin entrar jamás a la tierra prometida.

A propósito de esto, es interesante notar algunos señalamientos de la lectura levinasiana evocando el Talmud en lo concerniente al privilegio que esta obra de interpretación da a la lengua griega en cuanto a la traducción de las Escrituras:

Ciertamente, siempre habrá que desmetaforizar las metáforas, incluso aquellas por las cuales acabamos de desmetaforizar las metáforas y torcerle el cuello a la elocuencia. Hace falta paciencia. Pero entonces esta escuela del habla paciente es también lo precioso de nuestra herencia griega (Á l'heure des nations, 65, trad. mía).

Un "habla paciente" que se pudiese traducir — tal vez — por la escucha del otro. La pasividad - el tiempo en tanto que paciencia- no se dice "en el cuerpo" de las letras cuadradas, pero tampoco se dice en griego, es el gesto traductor del filósofo, ambidiestro, ambiguo: escribiendo de derecha a izquierda y de izquierda a derecha también; el contrabandista incansable tiene una tarea infinita, la de pasar la palabra del otro hacia otros. 


\section{REFERENCIAS}

Benjamin, Walter, "La tarea del traductor", en Angelus Novus, Barcelona, Edhasa, 1971.

Benveniste, Émile, "Categorías del pensamiento y categorías de la lengua”, en Problemas de lingüística general, México, Siglo XXI, 1993.

ButLer, Judith, Lenguaje, poder e identidad, Madrid, Síntesis, 1997.

Derrida, Jacques, Schibboleth, pour Paul Celan, Paris, Galilée, 1986.

_- entrevista con Antoine Spire en Staccato, programa televisivo en France Culture, 6 de julio de $1999<$ http://www.jacquesderrida.com.ar/textos/fenomenologia.htm>.

Husserl, Edmund, Meditaciones cartesianas, México, Fondo de Cultura Económica, 1996.

Levinas, Emmanuel, Difficile Liberté, Paris, Albin Michel, 1963. , Théorie de l'intuition dans la phénoménologie de Husserl, Paris, Vrin, 1963. Trad. en español: La teoría fenomenológica de la intuición, Salamanca, Ediciones Sígueme-Epidermis, 2004 (Hermeneia, 62).

—_, Totalité et infini (TI), La Haye, Martinus Nijhoff, 1971. Trad en español: Totalidad e Infinito (TI), Salamanca, Sígueme, 1987.

__, Autrement qu'être ou au-delà de l'essence, La Haye, Martinus Nijhoff, 1974. Trad. en español: De otro modo que ser o más allá de la esencia (DOMS), Salamanca, Sígueme, 1987.

_- Noms propres, Montpellier, Fata Morgana, 1976.

—, De l'évasion (DE), Montpellier, Fata Morgana, 1982. En español: De la evasión, Madrid, Arena Libros, 1999).

__, À l'heure des nations (HN), Paris, Minuit, 1988.

—, Quelques réflexions sur la philosophie de l'hitlérisme (QRPH) [1934], Paris, Payot et Rivages, 1997. Trad. en español: Algunas reflexiones sobre la filosofía del hitlerismo, Fondo de Cultura Económica, Buenos Aires, 2001.

Malka, Salomon, Monsieur Chouchani. L'énigme d'un maître du XXe siècle, La Flèche [Francia], J. C. Lattès, 1994.

PoIrIÉ, François, Emmanuel Lévinas, Besançon [Francia], La Manufacture, 1992. 
Rosenzweig, Franz, La estrella de la redención, Salamanca, Sígueme, 1997.

Traverso, Enzo, Cosmópolis. Figuras del exilio judeo-alemán, México, Universidad Nacional Autónoma de México, Instituto de Investigaciones Filológicas, Seminario de Poética-Fundación Cultural Eduardo Cohen, 2004.

Wohlfarth, Irving, Hombres del extranjero, México, Taurus, 1999. 
